TECHNICAL WORKING PAPER SERIES

\title{
THE CONVENTIONAL TREATMENT OF SEASONALITY IN BUSINESS CYCLE ANALYSIS: DOES IT CREATE DISTORTIONS?
}

\author{
Lawrence J. Christiano \\ Richard M. Todd \\ Technical Working Paper 266 \\ http://www.nber.org/papers/T0266 \\ NATIONAL BUREAU OF ECONOMIC RESEARCH \\ 1050 Massachusetts Avenue \\ Cambridge, MA 02138 \\ December 2000
}

The authors thank R. Anton Braun, Martin Eichenbaum, Philip Franses, Eric Ghysels, Charles Plosser, Tom Sargent, Christopher Sims, Mark Watson, and an anonymous referee for helpful comments and discussions. The first author acknowledges the financial assistance of the National Science Foundation. The views expressed in this paper are those of the authors and not necessarily those of the National Bureau of Economic Research.

(C) 2000 by Lawrence J. Christiano and Richard M. Todd.. All rights reserved. Short sections of text, not to exceed two paragraphs, may be quoted without explicit permission provided that full credit, including (C) notice, is given to the source. 
The Conventional Treatment of Seasonality in Business Cycle Analysis:

Does it Create Distortions?

Lawrence J. Christiano and Richard M. Todd

NBER Technical Working Paper No. 266

December 2000

JEL No. C0, E0

\section{$\underline{\text { ABSTRACT }}$}

'No.' So says one model that is broadly consistent with postwar U.S. seasonal and business cycle data.

Lawrence J. Christiano

Northwestern University Department of Economics

2003 Sheridian Road

Evanston, Illinois 60208

NBER and the Federal Reserve

Bank of Chicago and Cleveland

1-christiano@nwu.edu
Richard M. Todd

c/o Risk Management Department

Federal Reserve Bank of Minneapolis

P.O. Box 291

Minneapolis, MN 55480

dick.todd@mpls.frb.org 


\section{Introduction}

Large, recurring seasonal movements are a prominent feature of many economic data series, such as GDP, hours worked, and consumption. For many variables, seasonal fluctuations are even larger than business cycle fluctuations. Despite this, conventional business cycle analysis simply puts seasonality out of sight and out of mind: the data are seasonally adjusted at the source, and aseasonal models are used for the analysis. In effect, private agents are treated as though the seasonally adjusted data are what they see and choose. This paper is motivated by a concern that conventional practice may, by discarding information about the seasonal, distort the analysis of business cycles.

One can describe well-specified economic environments which rationalize the conventional treatment of seasonality. We illustrate this with a simple example. However, it has three very restrictive features: (i) seasonality is perfectly forecastable and enters the exogenous shocks additively; (ii) seasonal adjustment is accomplished by regression on seasonal dummies; and (iii) the optimal policies of agents are linear in the exogenous shocks. There is universal agreement that none of these features hold exactly in realistic applications. Still, in what Thomas Sargent (1978) calls "economists' ancient hunch", conventional practice implicitly assumes the conditions are satisfied as a rough approximation. In this paper, we devise and apply a method to study the quality of that approximation.

We begin by constructing a seasonal business cycle model that captures broad features of US seasonally adjusted and unadjusted macroeconomic data. We then use the model to generate artificial data that we treat as if they were the true US seasonally unadjusted data. These data are seasonally adjusted using a version of the method used by the US government. The data are then given to a hypothetical analyst, who studies them using the conventional practice. In particular, the analyst applies the Hodrick and Prescott (1997) (HP) filter to the artificial data and computes various second moments. ${ }^{1}$ The analyst constructs an aseasonal model, parameterizes it using standard calibration methods, and then computes the model's business cycle implications. We show that the second moment properties in the (artificial) data match those of the analyst's model very closely. We interpret this as indicating that, in our model, the ancient hunch is verified.

For the implications of our model to be of relevance to applied work, it is critical that it be empirically credible. We thus devote a considerable portion of the paper to explaining and defending the model's construction. The degree to which seasonals are forecastable is particularly important to the outcome of our analysis (see Plosser (1979)) and is also highly controversial (see, e.g., Franses, Hoek, and Paap (1997), Hylleberg, Jorgensen, and Sorensen

\footnotetext{
${ }^{1}$ To insure robustness, we repeat our analysis with the HP filter replaced by the first-difference filter. Our basic conclusions are not substantively affected by this change.
} 
(1993)). As a result, we pay particular attention to this issue.

The plan of the paper is as follows. The first section below presents a very simple example to illustrate a set of restrictions on a model and data that rationalize the conventional treatment of seasonality. We indicate there what factors are likely to lead to distortions, so that we may be mindful of them as we construct the seasonal model used in the main analysis. Section 3 describes that model. Section 4 discusses how we chose values for its parameters. Some points of potential independent interest emerge in this discussion, such as that the seasonal pattern in hours worked and productivity is very sensitive to how hours worked are measured. Section 5 provides evidence on the goodness-of-fit of our seasonal model. Section 6 describes the models estimated by the hypothetical analyst who applies the conventional practice. Section 7 presents our basic results and describes how well the analyst using the conventional practice is able to understand the business cycle properties of the data. Section 8 presents concluding remarks.

\section{Conventional Practice, and Where It Can Go Wrong}

We describe an environment in which the implicit assumptions underlying the conventional treatment of seasonality are exactly true. We then highlight the three restrictive features in the example that were noted in the introduction, and point out why they are unlikely to be satisfied in practice. This motivates the analysis in the remainder of the paper, which abandons environments in which these features are satisfied exactly.

\subsection{A Simple Model}

In the model, consumption, $C_{t}$, and the beginning of period stock of capital, $K_{t}$, solve the following problem:

$$
\max E_{0} \sum_{t=0}^{\infty} \beta^{t} \ln \left(C_{t}\right),
$$

subject to:

$$
Y_{t}=C_{t}+K_{t+1}-(1-\delta) K_{t}, Y_{t}=e^{x_{t}} K_{t}^{\alpha},
$$

where $E_{0}$ denotes the date 0 conditional expectation, $K_{0}$ is given and,

$$
\begin{aligned}
x_{t} & =x_{t}^{n s}+x_{t}^{d} \\
x_{t}^{n s} & =\rho x_{t-1}^{n s}+\varepsilon_{t}, \varepsilon_{t} \sim N\left(0, \sigma^{2}\right), \\
x_{t}^{d} & =-s, t \text { odd } \\
x_{t}^{d} & =s, t \text { even. }
\end{aligned}
$$


Here, $\alpha, \rho, \beta \in(0,1)$. We think of the time period in the model as being 6 months, so that it is a simple model of seasonality. When $\delta=1$, then the equilibrium stock of capital for this model evolves as follows:

$$
\ln K_{t+1}=\ln \alpha \beta+\alpha \ln K_{t}+x_{t}^{n s}+x_{t}^{d},
$$

given $K_{\mathbf{0}}$ and for $t=0,1,2, \ldots$. Equilibrium $Y_{t}$ and $C_{t}$ are found by substituting the equilibrium capital stock into (2.2).

The capital stock that solves (2.4) can be expressed as the sum of what it would be if there were no seasonal, plus a pure seasonal term, after taking natural logs. Specifically,

$$
\ln K_{t}=\ln K_{t}^{n s}+d_{t}^{K}
$$

where $K_{t+1}^{n s}, t=0,1,2, \ldots$, solves $(2.4)$ with $x_{t}^{d} \equiv 0$ and $\log K_{\mathbf{0}}^{n s}=\log K_{0}-d_{0}^{K}$. Also,

$$
d_{t}^{K}=-\frac{1}{1+\alpha} x_{t}^{d}, t=0,1, \ldots
$$

To verify that $(2.5)$ is a valid decomposition of $\ln K_{t}$, it is sufficient to confirm that $d_{t+1}^{K}=$ $\alpha d_{t}^{K}+x_{t}^{d}$ for $t=0,1,2, \ldots$.

We can obtain a similar decomposition for gross output, $Y_{t}$, based on the production function, (2.2):

$$
\ln Y_{t}=\ln Y_{t}^{n s}+d_{t}^{Y},
$$

where

$$
\begin{aligned}
d_{t}^{Y} & =x_{t}^{d}+\alpha d_{t}^{K}, \\
\ln Y_{t}^{n s} & =x_{t}^{n s}+\alpha \ln K_{t}^{n s} .
\end{aligned}
$$

Here, $Y_{t}^{n s}$ is the level of output that would occur if there were no seasonal. Actual output is this term, plus a seasonal dummy, after taking logs.

\subsection{Conventional Practice, Rationalized}

We now describe a stylized representation of conventional practice in the business cycle literature. Consistent with the treatment of $\beta$ in that literature, we simply assume the analyst knows its true value without having to estimate it. We also assume the analyst knows the basic structure of the model. We suppose the analyst knows the true value of $\alpha$ because, say, the share of income earned by capital in the economy is published in a 
set of national income accounts. The parameters of the time series representation of $x_{t}^{n s}$ is estimated based on the seasonally adjusted data.

We suppose that the government in this economy compiles observations on $K_{t}$ and $Y_{t}$. Before providing the data to the business cycle analyst, seasonal adjustment is carried out by first computing the residuals from a least squares regression of $\ln K_{t}$ and $\ln Y_{t}$ on seasonal dummies, and then adding back the sample averages of the raw data. With this seasonal adjustment procedure (applied in a large sample of data) the data available to the analyst are $\ln K_{t}^{n s}$ and $\ln Y_{t}^{n s}$.

With the seasonally adjusted data in hand, we suppose the analyst follows conventional practice by computing technology shocks as $\ln Y_{t}^{n s}-\alpha \ln K_{t}^{n s}$. Note that this produces exactly $x_{t}^{n s}$. With a large sample of data, the analyst can then find $\rho$ and $\sigma$ in (2.3) by using standard regression analysis.

Having calibrated the model, the analyst compares the business cycle properties of the model with the business cycle properties in the (seasonally adjusted) data. In this example, the analyst finds that the model and the data mesh exactly. This is true, whether or not the seasonally adjusted and logged data are both HP filtered.

\subsection{Potential Pitfalls for Conventional Practice}

In the example, the seasonally adjusted data available to the analyst, together with the implied values for the exogenous shocks and parameters, solve the true model. The example rationalizes conventional practice perfectly. But, should these implications of the example be taken seriously?

In practice, none of the three crucial features of the example (features (i)-(iii) highlighted in the introduction) are likely to be satisfied. For example, suppose seasonality did enter additively in the exogenous shocks, as in (i), but that the seasonal component were not perfectly predictable. In this case, agents must guess whether a given movement in exogenous shocks reflects a change in the seasonal or nonseasonal component, forcing them to respond to any movement, seasonal or nonseasonal, as though it reflects a mixture of both. So, the seasonally adjusted version of agents' consumption, investment, employment, etc., decisions will be a function, in part, of the seasonal component of the exogenous shocks. ${ }^{2}$

Consider the role of the seasonal adjustment procedure. Our analysis of the dummy seasonal adjustment method exploits its properties of idempotency (i.e., $h[h(x)]=h(x)$, where $h$ is the filter and $x$ denotes the raw data) and linearity $(h(x+y)=h(x)+h(y)) .^{3}$

\footnotetext{
${ }^{2}$ See Ghysels (1988), Plosser (1979) and Sargent (1987, pp. 336-342) for further discussion.

${ }^{3}$ For a discussion of the idempotency and linearity of the dummy seasonal adjustment procedure, see Lovell (1963).
} 
These properties are at best only approximately true when a procedure like the official Census $\mathrm{X}-11$ procedure is applied.

Finally, unlike (2.4), the policy rules that solve models analyzed in practice are not exactly linear. At the very least, we can expect coefficients on endogenous variables to vary with the seasons. If agents' decision rules were a nonlinear function of the seasonal and nonseasonal components, then conventional seasonal adjustment procedures would not separate their decisions into a part exclusively related to the seasonal component and a part exclusively related to the nonseasonal component. An example is consumption, $C_{t}$, in the model economy described above. It is not a linear or log-linear function of the exogenous shocks. As a result, it does not have the exact decomposition depicted in (2.5) or (2.6).

These criticisms of the conventional practice are not conclusive because the considerations raised above may not be quantitatively important. ${ }^{4}$ Although their position is not universally accepted, Barsky and Miron (1989) argue that the seasonal component in many macroeconomic time series can be well represented by deterministic shifts in constant terms. Regarding the seasonal adjustment filter, Cleveland and Tiao (1976), Wallis (1974), and Young (1968) argue that the Census X-11 procedure is nearly linear. ${ }^{5}$ Also, while not exactly idempotent, the procedure may be nearly so. Finally, it has been noted that the decision rules that solve many modern macroeconomic models are very close to linear (see Christiano 1990). Near dummy seasonality plus near linear decision rules plus a seasonal adjustment procedure that is nearly linear and idempotent would presumably imply little distortion.

\section{Our Seasonal Model}

This section presents the main seasonal model used in our analysis. We begin by presenting our assumptions on preferences and technology. We then discuss the time series representations for the exogenous shocks.

\footnotetext{
${ }^{4}$ We wish to differentiate this defense of standard practice from Hansen and Sargent (1993) and Sims (1976)'s defense. They emphasize that modeling seasonality explicitly, but with an incorrect specification of the seasonal, also leads to distortions. These distortions, they argue, can exceed those that ar ise from the standard practice. We do not consider their argument in this paper. But, we view it as potentially complementary to our finding that the distortions in standard practice may be small.

${ }^{5}$ Ghysels, Granger and Siklos (1996) argue that there is a sense in which the X-11 is not so close to linear. As noted by a referee, the nonlinearity in the Census X11 procedure reflects, in part that it involves a sequence of discrete decisions (whether to adjust or not, whether to adjust multiplicatively or additively, etc.).
} 
The preferences of the representative household are as follows:

$$
E_{\mathbf{0}} \sum_{t=0}^{\infty} \beta^{t}\left[\tau_{t} \ln \left(C_{t}\right)+\ln \left(T-n_{t}\right)\right], 0<\beta<1,
$$

where $n_{t}$ denotes hours worked, $\tau_{t}$ is a taste shock process whose time series representation is presented below and $T$ is the time endowment.

Per capita output, $Y_{t}$, is produced via the Cobb-Douglas production function

$$
Y_{t}=K_{t}^{\alpha}\left(z_{t} n_{t}\right)^{1-\alpha}
$$

where $z_{t}$ is an aggregate shock to technology and $0<\alpha<1$. The technology shock has the representation

$$
z_{t}=z_{t-1} e^{\lambda_{t}}
$$

and the time series model for $\lambda_{t}$ is described below.

Investment projects require four quarters to complete. Projects started in period $t, S_{t}$, contribute to the evolution of the capital stock as follows:

$$
K_{t+4}-(1-\delta) K_{t+3}=S_{t}, 0<\delta<1
$$

where, as in the previous section, $\delta$ denotes the depreciation rate on capital. Period $t$ starts require the application of $\omega_{0, t} S_{t}$ resources in the current quarter; $\omega_{1, t} S_{t}$ in the next quarter; $\omega_{2, t} S_{t}$ in the following quarter and $\omega_{3, t} S_{t}$ in the final quarter of the project. We use the time subscripts in the $\omega_{i, t}$ 's to accommodate seasonal variation, as discussed below. Total investment in period $t$ is the sum of resources required by projects started in the current and previous three quarters:

$$
I_{t}=\omega_{0, t} S_{t}+\omega_{1, t-1} S_{t-1}+\omega_{2, t-2} S_{t-2}+\omega_{3, t-3} S_{t-3}
$$

The aggregate resource constraint is:

$$
Y_{t} \leq C_{t}+I_{t}+G_{t}
$$

where $G_{t}$ denotes government consumption. We adopt a modified version of Christiano and Eichenbaum's (1992) model of $G_{t}$ :

$$
G_{t}=g_{t} z_{t} .
$$

We now discuss the time series representation of $g_{t}$ and the other exogenous shocks, $\tau_{t}$ and $\lambda_{t}$. The considerations emphasized in the introduction suggest that we must be flexible 
regarding the degree of predictability in the seasonal component of these variables. The time series representations used in Barsky and Miron (1989) suit our purposes:

$$
\ln x_{t}=x_{t}^{d}+x_{t}^{n d}
$$

for $x=\tau, \lambda, g$. In (3.8), $x_{t}^{d}$ is a deterministic sequence of seasonal dummies with period 4 , and $x_{t}^{n d}$ is the following zero-mean covariance stationary process:

$$
\left(1-\phi_{1} L-\phi_{2} L^{2}\right)\left(1-\theta L^{4}\right) x_{t}^{n d}=\varepsilon_{t},
$$

where $\varepsilon_{t}$ is a mean-zero, independent and identically distributed Normal variable with variance $\sigma^{2}$. Here, $L$ denotes the lag operator. The representation for $x_{t}^{n d}$ in (3.9) allows for an indeterministic seasonal component when $\theta \neq 0$. We call (3.8)-(3.9) our baseline shock model. The version of our model that incorporates this representation of the shocks is called the baseline seasonal model.

To guard against bias in favor of models with deterministic seasonality, we also consider an alternative shock model in which all seasonality is forced into the indeterministic part of $\ln x_{t}$. In that model, $x_{t}^{d}$ is simply a constant for all $t$ and $x_{t}^{\text {nd }}$ has a high-order autoregressive representation. Modifications of our baseline seasonal model that incorporate this representation for one or all of the shocks yield our alternative seasonal models.

The endogenous variables of the model maximize (3.1) subject to the various constraints described. The method we use to approximate the model's solution corresponds to the one implemented by Braun and Evans (1995). It is important to emphasize that, although our solution method is based on linearization, it does not force the solution to linearly decompose into the sum of seasonal and non-seasonal components. Our model solution procedure (log) linearizes around the model's seasonally varying steady state growth path. ${ }^{6}$ Thus, the solution takes the form of four distinct decision rules, one for each season. In principle, this is consistent with a linear decomposition, if all the seasonal variation appeared in the constant terms. However, the solution method also permits seasonal variation to appear in slope terms, in which case the data cannot be linearly decomposed into seasonal and nonseasonal parts.

\section{Parameterizing the Seasonal Model}

This section discusses how we picked the parameter values for our seasonal models. There are two types of parameters, those that vary with the seasons and those that do not. For

\footnotetext{
${ }^{6}$ Our method is similar to the one implemented by Braun and Evans (1995).
} 
the latter, we simply adopt the values in Christiano and Eichenbaum (1992): $T=1369$, $\delta=.021, \beta=1.03^{-0.25}$, and $\alpha=0.34$. Their rationale for choosing these parameter values applies in our context too. The seasonal parameters - the time-to-build weights and those that describe the time series representations of the exogenous stochastic processes - must be estimated using seasonally unadjusted data. The data that we use are described in the first subsection below.

The second subsection estimates our baseline shock models. Our point estimates attribute much of the seasonal movements in the taste and technology shocks to deterministic dummies. We discuss the interpretation of the temporal pattern of these dummies, which we find plausible. Indeterministic seasonality plays a relatively more important role in the government consumption shock process.

The discussion in section 2 suggests that our baseline point estimates may tilt our results in favor of the conventional practice on seasonality. To inoculate ourselves against bias we undertake an additional estimation exercise in the third subsection below. There, we estimate our alternative shock models, which are purely indeterministic and which exclude deterministic seasonality altogether. These models are subjected to statistical tests in Appendix B. The tests reject the alternative shock model in the case of the taste and technology shocks, but do not reject it in the case of the government spending shock. ${ }^{7}$ We interpret the outcome of this test as consistent with the notion, suggested by our baseline shock model estimation results, that deterministic seasonality is important in the taste and technology shock processes. Still, robustness considerations lead us to use both our baseline and alternative shock models in the analysis reported in later sections.

The final subsection below estimates the time-to-build weights of our seasonal model. These are selected to ensure that the model replicates the observed seasonal pattern in investment. The resulting estimated weights are consistent with microeconomic evidence on investment projects.

\subsection{The US Data}

With one exception, we use the seasonally unadjusted quarterly data compiled by Barsky and Miron (1989) for the period 1946-85. The exception is the data on total hours worked. We argue in Appendix A that the Barsky and Miron data, based on the establishment survey for the period 1964-85, are misleading for the purpose of understanding seasonal

\footnotetext{
${ }^{7}$ Without further restrictions, descriminating between indeterministic and deterministic seasonality is not possible in a finite data set. In our test we impose the restrictions that the indeterministic and deterministic models are particular parametric representations of the data. With these additional restrictions, our test is a meaningful one. For further discussion, see Appendix B.
} 
fluctuations. We claim there that a better measure of hours worked is the one based on a survey of households, and adjusted for workforce composition by Gary Hansen (1993). Hansen's quarterly efficiency hours data start in 1955 and were converted into per capita terms by dividing by the population aged 20-65. The other data used in this analysis were also converted into per capita terms in this way. Finally, the investment data series that we construct from the Barsky-Miron data set corresponds to business fixed investment, while the consumption data corresponds to consumption of nondurables and services.

\subsection{Baseline Shock Models}

Given the aseasonal parameter values taken from Christiano and Eichenbaum (1992) and the equations of our model, we use the data to compute an implied time series for each of our exogenous shocks. We then use these time series to estimate our baseline time series representation, (3.9), for each exogenous shock process. In each case, we estimate model (3.8)-(3.9) in two steps. The first step involves regression on seasonal dummies. The second step fits model (3.9) to the fitted disturbances from the step-one regression using standard time series methods.

\subsubsection{Taste Shocks}

Consider the taste shock first. To compute the implied time series for the taste shock, we used the intratemporal first-order condition corresponding to the hours decision. In terms of the variables defined in the previous section, this is expressed as

$$
\tau_{t}=\frac{C_{t} n_{t}}{Y_{t}\left(T-n_{t}\right)(1-\alpha)}
$$

The logarithm of the taste-shock data is displayed in Figure 1a. Note how the last few observations rise substantially, as though they were drawn from a different population than the preceding observations. Because of this, and in order to avoid issues of potential nonstationarity, we dropped the last 8 observations for purposes of estimating a time series representation for these series. We also dropped the first 12 observations, to maintain consistency with the periods of apparent stationarity of the government shock series (see below).

The $R^{2}$ of the regression of the log-taste shock on dummies is 0.57 , suggesting that the dummy variables account for more than 50 percent of the variation in the taste shock. We tested the joint null hypothesis that all the dummies are equal. The resulting test statistic, 359, is a realization from a Chi-square with three degrees of freedom under the 
null hypothesis. ${ }^{8}$ Thus, the null hypothesis is overwhelmingly rejected. This evidence is consistent with the hypothesis that there is an important deterministic seasonal in the data. ${ }^{9}$

Panel A of Table 1 reports the estimation results for the taste shock model. Note that the parameter indexing the indeterministic seasonal, $\theta$, is not significantly different from zero. We nonetheless retain the point estimate of $\theta$ in our baseline shock model. ${ }^{10}$ The taste dummies appear to have a reasonable interpretation. They imply that the relative preference for consumption versus leisure is almost constant in quarters 1 and 2. There is a shift in favor of leisure in quarter three, and then a stronger shift back to consumption in the fourth quarter. We interpret the shift in favor of leisure in quarter three as a preference for vacations in the summer, and the shift in favor of consumption in the fourth quarter as reflecting the effects of the winter holiday season.

\subsubsection{Technology Shocks}

To compute the technology shock series, $\lambda_{t}$, we used the model's production function:

$$
\lambda_{t}=\ln z_{t}-\ln z_{t-1}, \quad \ln z_{t}=\frac{\left[\ln y_{t}-\alpha \ln k_{t}-(1-\alpha) \ln n_{t}\right]}{1-\alpha} .
$$

For this calculation, we used our value of $\alpha=0.34$, the effective household hours series for $n_{t}$, and Barsky and Miron's GNP series for $y_{t}$. For $k_{t}$ we used Christiano's (1988) capital stock series. ${ }^{11}$

The $\lambda_{t}$ time series, graphed in Figure 1b, shares some features of the taste shock series. It seems to be strongly seasonal but otherwise can be viewed as potentially stationary except near the ends of the sample. We used the same time interval and econometric method as for

\footnotetext{
${ }^{8}$ The test was implemented in RATS using the Newey-West procedure for adjusting for heteroscedasticity and for autocorrelation up to order 6 . For this, we used the ROBUSTERRORS option with $\mathrm{DAMP}=1$ and $\mathrm{LAGS}=6$ in the RATS regression procedure, LINREG.

${ }^{9}$ There is evidence that the $R^{2}$ statistic may spuriously inflate the importance of deterministic seasonals (Franses, Hylleberg, and Lee 1995). To avoid being misled by this possibility, we take two steps. First, as emphasized above, we repeat our analysis with purely indeterministic representations for the exogenous shocks. Second, Appendix B develops additional statistics for assessing the importance of a deterministic component in seasonality.

${ }^{10}$ In calculations not reported here, we verified that setting to zero all insignificant coefficients in estimates of equation (3.9) for $\tau$ (and also for $\lambda$ ) does not significantly change our results on the effects of standard business cycle practice.

${ }^{11}$ Strictly speaking, this capital stock series is inappropriate for backing out a seasonal technology shock, because it is constructed from seasonally adjusted data. The shock series we construct may thus exaggerate the seasonality in productivity, although we believe the effect is small because seasonal variations in the capital stock are probably very small.
} 
the taste shock to estimate the baseline shock model, (3.8)-(3.9). The $R^{2}$ in the first-step regression is 0.88 , suggesting that the seasonal dummies explain about 88 percent of the total variation in the growth rate of technology. We again tested the joint null hypothesis that all the dummies are equal. The resulting test statistic, 667, is a realization from a Chisquare with three degrees of freedom under the null hypothesis. This is a strong rejection and is consistent with the notion that there is an important deterministic component in the technology seasonal.

The results in Panel B of Table 1 suggest, as in the case of the taste shock series, that the seasonal in technology is primarily deterministic. To see this, note that $\theta$ is not statistically different from zero. The results there show that the other autoregressive coefficients are also not statistically different from zero. Nonetheless, for our baseline shock model for technology growth we use the point estimates in Panel B.

The estimated quarterly dummies in Panel B of Table 1 indicate that technology growth turns sharply negative in the first quarter, rebounds substantially in the second quarter, and then continues at a moderate pace in quarters 3 and 4. The first quarter plunge in technology has been linked to winter weather (Barro 1990, p.273). ${ }^{12}$ Overall, the seasonal pattern of dummies seems consistent with the interpretation of $\lambda$ as an exogenous technology process. ${ }^{13}$

\subsubsection{Government Consumption Shocks}

We used our $z_{t}$ data and Barsky and Miron's $G_{t}$ data to construct $g_{t}$ using (3.7). The $g_{t}$ data are graphed in Figure 1c. Regression analysis shows that seasonal dummies explain relatively little (the $R^{2}$ is 12 percent) of the total variation in government spending. When we tested the null hypothesis that the dummies in each quarter are identical, we obtained a test statistic of 29 , which is a realization from a Chi-square distribution with three degrees of freedom under the null hypothesis. As before, we reject the hypothesis that there is no deterministic seasonal. However, we do so less massively than before. This is consistent with the notion that the deterministic component of the seasonal in government consumption is relatively smaller than it is in the other shock series.

The baseline government shock model is shown in Panel C of Table 1 . In this model, there is relatively more evidence of serial correlation in the fitted disturbances (the Q statistic has significance level 0.09), but it is adequate for our purposes.

\footnotetext{
${ }^{12}$ The importance of winter weather as an explanation of the first quarter dip in productivity has been challenged (Beaulieu and Miron 1991).

${ }^{13}$ When $\lambda$ is computed using the Barsky-Miron hours worked data, the interpretation of the result as exogenous technology is more problematic. In Appendix A we argue that the problems stem fundamentally from the fact that their hours worked data are inappropriate in the present context.
} 


\subsection{Alternative Shock Models}

In this section, we estimate our alternative shock models, which specify that all seasonality is indeterministic. We do this by fitting autoregressive representations, with constant terms but no dummies, to each shock series, using the same data and time period as before. In selecting the lag length for these representations, we used the Schwarz (1978) criterion. To conserve space, we do not report our results in detail. The Schwarz criterion selected lag lengths of 8,8, and 9, respectively, for the taste shock, the technology shock, and the government consumption shock, although a 4-lag specification for technology was a close second. As expected, the coefficients on seasonal lags in these autoregressions were generally positive and statistically significant. Conventional goodness-of-fit measures suggest that these indeterministic models fit the data about as well as our baseline shocks models.

However, further tests executed in Appendix B decisively reject the alternative shock model for taste shocks. The alternative shock model is generally also rejected for the technology shocks, although not by all the tests. Finally, we could not reject the alternative shock model using government consumption shocks. In light of these findings and out of concern for robustness, we analyze alternative seasonal models in which the exogenous shocks are represented by the alternative shock models.

\subsection{Time-to-Build Weights}

The only parameters that remain to be estimated are the time-to-build weights. Our strategy for doing this is to match the steady state seasonal movements in the model's investment data with the analogous movements in the data. In the model and the data, these movements are characterized by four numbers. In the model, these are the four values of logged, HP-filtered investment that occur in the nonstochastic steady state of the baseline seasonal model. ${ }^{14}$

\footnotetext{
${ }^{14}$ By non-stochastic steady state, we mean the model variables along a deterministic growth path in which all shock innovations are held equal to their unconditional mean of zero.

To compute the model's implications for HP-filtered, log investment in nonstochastic steady state, we proceed as follows. Let $g(L)$ denote the lag-operator representation of the HP filter as derived in, say, King and Rebelo (1993). Here, $L$ is the lag operator, so that $L^{j} x_{t} \equiv x_{t-j}$. Then, compute the weights, $g_{j}$, in the two-sided, infinite-ordered expansion, $g(L)=\sum_{j} g_{j} L^{j}$. Let $i_{t}$, for $t=-\infty, \ldots, \infty$ denote the two-sided, infinite sequence of $\log$, scaled investment. This is constructed from four seasonal numbers, one for each quarter in the year, repeated in each year. Given the simple pattern in $i_{t}$ and the $g_{j}$ 's, it is straightforward to compute $g(L) i_{t}$. This is also a doubly infinite sequence, constructed from four numbers, one for each season in the year. This gives us HP-filtered, log scaled investment. To undo the effects of the scaling, we add the HP filter of the logged scale variable, evaluated in nonstochastic steady state, to obtain the result that we seek.
} 
In the data, the four numbers are the average percentage deviation of log investment from its HP-trend in each quarter. The latter are exhibited in the row of Table 2 associated with investment, $I$. That row indicates that logged investment is about 9 percent below its HP-trend in the first quarter and about 3 percent above in the other three quarters.

To implement our strategy we have to drastically reduce the number of free parameters in the time-to-build weights, $\left\{\omega_{i, t}\right\}$. We reduce the number of parameters to four by imposing the following restrictions:

$$
\begin{aligned}
\omega_{i, t} & =\omega_{i} \geq 0, \text { for } i=1,2,3, \text { all } t \\
1 & =\omega_{0, t}+\omega_{1}+\omega_{2}+\omega_{3}, \text { if } t \text { is not in the first quarter of a year } \\
\omega_{0, t} & \geq 0 \text { for all } t .
\end{aligned}
$$

The weights in stages 1,2 and 3 are allowed to be different, but they do not depend on the quarter of the year in which the project was started. ${ }^{15}$ The only weight that is allowed to vary with time is $\omega_{0, t}$. We used a nonlinear equation solving routine to find values of the four choice variables to hit the four targets.

The time-to-build weights obtained by this procedure, shown in Table 3, differ significantly from the fixed weight of 0.25 used by Kydland and Prescott (1982) in their original time-to-build model. Most importantly, our weights display the slow start-up, or time-toplan, property highlighted by Christiano and Todd (1996). That is, the resource cost of the first stage of a project is much lower than the subsequent stages. See Christiano and Todd for a review of the microeconomic evidence on investment projects, which favors this specification. Another feature of the estimated weights is that the cost of starting a project in the first quarter, though still low, is higher than in other quarters. We conjecture that this feature of the weights is important in matching the data because it helps offset the disincentive to invest in the model's first quarter arising from the seasonally low state of technology in that quarter. It does so in two ways. First, for a fixed seasonal pattern of starts, the increase has a direct, positive effect on first quarter investment. Second, by raising the total resource requirement of projects started in the first quarter, it creates an incentive to push starts into other quarters. This has the effect of shifting the more resource intensive stages of investment projects towards the first quarter.

\footnotetext{
${ }^{15}$ Some sort of variation in the $\omega_{i, t}$ 's by stage of project, $i$, is necessary in our model, to accommodate the seasonal variation in investment. It is easily verified that if the weights did not vary with $i$, then even if starts exhibited a seasonal pattern, steady state investment would not.
} 


\section{Empirical Evaluation of the Baseline Seasonal Model}

For our analysis to be credible, it is necessary that the model used represent a reasonable abstraction of reality. In part, this requires that the laws of motion of the exogenous shocksparticularly their deterministic seasonal component-have a plausible interpretation. The previous section argues that the baseline seasonal model passes this test. This section evaluates the baseline seasonal model in terms of its ability to account for various first and second moment properties of the data. We argue that the model again does reasonably well.

\subsection{First Moments}

We consider two types of first moments. The first measures the scale over the seasons of various variables of interest. The second measures average deviations from trend over the seasons.

Table 4 reports measures of scale. The right side shows, for the baseline seasonal model, the non-stochastic steady-state values of hours worked and the ratios of investment, consumption, capital stock and government spending to output. The left panel reports the corresponding statistics, obtained by regressing the US data on quarterly dummies. (We do not report empirical results for the capital to output ratio, since we do not have seasonally unadjusted data on the capital stock.) With one exception, the match between model and data is good. The exceptional case is the investment to output ratio, which is higher in the model than in the data. Primarily, this reflects the absence of durable goods purchases from the Barsky-Miron investment data.

The right side of Table 5 reports, for the baseline seasonal model, the percent deviation, in non-stochastic steady state, of the indicated variables from their HP trend values. The left side reports the empirical analog, copied from Table 2 for ease of comparison. Note that the investment numbers line up exactly. That simply reflects our method for selecting the time-to-build weights. More significantly, the model captures many of the other basic features of the seasonal data. For example, output is weak in the first quarter and strong in the fourth, the volatility of the seasonal component of consumption roughly matches that of output, those two variables are highly seasonally correlated, and hours worked dips in the third quarter.

\subsection{Second Moments: The Seasonal Cycle}

Table 6 reports various second moment properties of seasonally unadjusted US data (Panel A) and of our baseline seasonal model (Panel B). The second moment properties of US seasonally unadjusted data were obtained by logging the data, HP filtering them, and then 
computing the second moments shown. For our baseline seasonal model, the results were computed by applying the same transformations to a synthetic data set of 2,000 observations generated from our baseline seasonal model.

The model has both strengths and weaknesses. On the strength side, note that the overall volatility of output in the model and the data are close, around 3.5-3.8 percent. This is a plus for the model, since the overall volatility of output played no direct role in selecting the model parameter values. Note also how consumption is roughly as volatile as output, both in the model and the data. The volatility of seasonally unadjusted consumption, discussed by Ghysels (1994b), shows how the seasonal cycle differs in some important respects from the business cycle. A key feature of the latter is that consumption is considerably smoother than income and output (see below for further discussion). Generally, the absolute and relative amounts of volatility in the model variables are in line with the data.

The model does reasonably well on dynamics. Note how it captures the persistence in output and the fact that productivity leads hours by two quarters.

A shortcoming of the model is that it overstates the contemporaneous correlations between productivity and hours and between government spending and output. We are less concerned about the latter, because the government spending shock plays a relatively small role in the model dynamics.

\subsection{Second Moments: The Business Cycle}

We now evaluate the model's ability to account for basic business cycle facts. The results in Table 7 allow us to compare the business cycle implications of the model (Panel B) with the data (Panel A). The business cycle properties of US data were obtained by first seasonally adjusting our data (see section 3.a) using a standard procedure, then logging it, HP filtering it, and computing the second moments shown. ${ }^{16}$ The results resemble those reported in the existing business cycle literature (see, for example, Cooley and Prescott (1995). $)^{17}$ Panel B reports the analogous statistics, computed from 2,000 synthetic data observations generated using our baseline seasonal model.

The baseline seasonal model has shortcomings, as well as successes. Turning to the successes, note that the model captures in a rough way the relative volatility and dynamic

\footnotetext{
${ }^{16}$ We seasonally adjusted the data using Estima's RATS386x EZX11 implementation of the US government's Census X11 multiplicative procedure.

${ }^{17}$ There is one sense in which the results are different. The volatility reported for output, 2.4 percent, in Table 7 is greater than the usual estimate of about 2 percent reported in the literature. This leads to a relatively low estimate for the relative volatility of hours worked to output. Presumably, the high estimate for the volatility of output reflects the price index (the CPI) used to convert nominal GNP to real GNP in the Barsky-Miron data.
} 
correlations of most of the variables. Also, it is quite successful in capturing the dynamic correlation of hours worked and productivity. In both the model and the data, the contemporaneous correlation is quite low. The model result is consistent with the argument in Christiano and Eichenbaum (1992), who claim that a business cycle model with multiple shocks is needed to match the observed low correlation of productivity and output. The fact that productivity leads hours worked in the model, as it does in the data, reflects the time-to-plan structure of the investment weights. This is discussed at length in Christiano and Todd (1996).

Now consider some of the model's shortcomings. First, it overstates the volatility of consumption and understates its dynamic correlation with output. Evidently, the seasonal adjustment procedure substantially reduces the relative volatility of consumption in the data (compare Tables 6 and 7), but not in the model. Second, the model implies that investment lags output over the cycle, while our empirical measure of investment is contemporaneous with output. As explained in Christiano and Todd (1996), this implication of the model reflects the time-to-plan feature of the investment weights. This has the effect of introducing a delay in the response of investment to a shock. The fact that our empirical measure of investment is coincident with output over the cycle reflects that it includes residential investment, which leads the cycle somewhat (see Christiano and Todd (1996) for a discussion of the empirical evidence). Business investment in structures and durables do lag the cycleprobably for the type of time-to-plan considerations incorporated in our model. ${ }^{18}$ So, we think there is some wisdom in the model's implications for investment. As a result, we think the mismatch between model and data regarding the output - investment dynamics is overstated in Table 7. Finally, as in the business cycle statistics, the model isn't close on the dynamic correlations of government consumption. But, as before, we discount this because the results below are not very sensitive to our choice of model for this series.

Although the model has the empirical minuses just stated (in one case, qualified), overall it appears to do reasonably well. Our reading of Table 7 is that, despite clear shortcomings, our model's ability to replicate business cycle statistics is good enough to support our goal of analyzing the effects of seasonal adjustment with an empirically relevant data generating mechanism.

\footnotetext{
${ }^{18}$ Time-to-plan considerations presumably have relatively less direct impact on business investment in durable goods. However, it may have an important indirect impact via complementarities between investment in business structures (where there is an important time-to-plan component) and durables.
} 


\section{Constructing Aseasonal Analog Models}

We now have a baseline and an alternative seasonal model to use as laboratories for quantifying the distortions in the conventional practice with respect to seasonality. The models will be used to generate artificial data, which will be seasonally adjusted and provided to a hypothetical business cycle analyst. The analyst uses the data to estimate an aseasonal business cycle model and evaluate its ability to account for the business cycle facts. This section discusses the analyst's estimation method and results.

The analyst's model has two types of parameters: those that pertain to the exogenous shocks, and those that do not. The latter parameters include the discount rate, the time-tobuild investment cost weights, capital's share in the production function, and the depreciation rate. The conventional way to estimate these uses the first-moments of the data. Since these properties are not significantly distorted by seasonal adjustment, with one exception we assume the analyst knows their true values. The exception pertains to the time-to-build weights. In this case, we specify that the analyst's estimates are the weights that apply to projects initiated in quarters 2, 3, and 4 (see Table 3). We thereby introduce a small distortion into the analysis, since presumably an actual analyst's estimates of the weights will also be influenced somewhat by the slightly different weights that apply to projects initiated in the first quarter.

To obtain data needed for purposes of estimating the parameters of time series models for the exogenous shocks, the analyst is assumed to follow conventional practice. The shocks are deduced using the model parameters already estimated, the intratemporal Euler equation, the production function, and the seasonally adjusted data on consumption, output, employment, capital, and government consumption. Each shock series was modeled as the sum of a constant term and an autoregression. For the constant term, the analyst uses the sum of the seasonal dummies. This is roughly the sample average that the analyst would estimate using a large sample.

In choosing the lag length for the autoregessions of the exogenous shocks, we have to confront a technical problem. The true autoregressive representation of the seasonally adjusted shocks is in fact of very high-order and has a seasonal pattern in its coefficients. Figures $2 \mathrm{a}$ - 2c use data from the baseline seasonal model to illustrate this point. The figures report $\log$ spectra for $\ln \tau_{t}, \lambda_{t}$, and $\ln g_{t}$. The lines indicated by ${ }^{*}$ 's are the spectra of the seasonally adjusted data used by the analyst. For comparison, the solid line is the spectrum of the seasonally unadjusted data. Both spectra are computed based on an artificial data set of 2,000 observations generated using the baseline seasonal model. ${ }^{19}$ Note the seasonal peaks in the spectra of the seasonally unadjusted data. More significant, from the present stand-

\footnotetext{
${ }^{19}$ The spectrum was estimated by the following procedure. Let $y_{t}$ denote the logged data. We
} 
point, are the seasonal dips in the spectra of the seasonally adjusted data. That standard seasonal adjustment methods, like the Census X-11 method that we use, produce these dips is well known, and indeed it has been shown that such dips are characteristic of seasonal adjustment procedures that are optimal under common assumptions (Grether and Nerlove 1970). To represent data with dips like these requires high-order lags with seasonal patterns in the coefficients. ${ }^{20}$

In view of the previous considerations, a careful time series analyst with a large sample of seasonally adjusted data would fit high-order autoregressions. ${ }^{21}$ In the shorter samples available in practice, high-order seasonal coefficients in autoregressions cannot be accurately estimated and the possibility of seasonal dips in seasonally adjusted data is ignored. Because we want to study the consequences of conventional practice, we have our hypothetical analyst ignore seasonal dips and instead fit low order autoregressions to the exogenous shock data. We set the lag length to three on the basis of evidence that an econometrician using seasonally adjusted data generated from the baseline seasonal model would probably not have gone to higher order lags in data sets of standard size. ${ }^{22}$

estimated the following regression by least squares:

$$
y_{t}=\alpha+\sum_{i=1}^{N} \phi_{i} y_{t-i}+\varepsilon_{t} .
$$

Let $\sigma$ denote the estimated standard error of the fitted residual in this regression, and let

$$
\begin{aligned}
S(z) & =\frac{\sigma^{2}}{\phi(z) \phi\left(z^{-1}\right)}, z=e^{-i \omega^{*}}, \\
\omega_{j}^{*} & =\frac{2 \pi j}{T}, j=0, \ldots, \frac{T}{2}, \\
\phi(z) & =\sum_{i=1}^{N} \phi_{i} z^{i} .
\end{aligned}
$$

The figure displays the graph of $\ln S(z)$ against $\omega$, where $\omega=\omega^{*} / \pi$. In the calculations, we use $T=400$ and $N=8$. We also tried $N=12$, but that made little substantive difference.

${ }^{20}$ Sims (1993) has called this pattern in the coefficients of high order autoregressions fit to seasonally adjusted data "unraveling of the seasonal adjustment." Maravall (1995) provides a general discussion of this problem and an example based on US GNP data.

${ }^{21}$ Obviously, the phenomenon just described for the baseline model applies to the alternative model too.

${ }^{22}$ For each shock series, we divided our sample of 2000 quarterly observations into 10 segments of length 200. On each of these, we used the Schwarz criterion to determine the appropriate lag length of an autoregressive model. Optimal lag lengths were almost always less than or equal to three. 
The log spectra of the third-order autoregressions estimated by the econometrician using baseline seasonal model data are reported as dashed line in the figures. Note how those lines essentially interpolate the spectrum of the seasonally adjusted data and miss the seasonal dip.

\section{Results}

In section 4 we used US data to construct various data generating mechanisms: the baseline seasonal model and alternative seasonal models. In section 6 , we described the aseasonal models that an analyst using conventional business cycle methods would estimate using seasonally adjusted, artificial data from these data generating mechanisms. This section evaluates the distortions implied by these methods: we compare the differences between the business cycle properties of the artificial data and of data generated by the econometrician's estimated model. We find almost no distortion when the data are generated by the baseline seasonal model.

We perform various experiments to evaluate the robustness of this result. We consider what happens when second moment properties are computed based on first differencing the data rather than applying the HP filter. We also consider what happens when the data are generated by the alternative seasonal models.

When the first difference filter is used and the data are generated by the baseline model, then distortions are again very small. However, distortions do emerge when the alternative seasonal models are used to generate the artificial data. These distortions are magnified when the first difference filter is used. Thus, significant distortions can be found working with the alternative seasonal model and using the first difference filter. However, these results should be kept into perspective. First, the alternative model is statistically rejected. Second, in practice the first difference filter is only rarely used in the analysis of business cycle models. ${ }^{23}$

We first describe the results based on the baseline seasonal model. We then consider the alternative seasonal models.

\subsection{Results Based on Baseline Seasonal Model}

Business cycle statistics computed from seasonally adjusted data generated by the baseline seasonal model are copied from Panel B of Table 7 to Panel A of Table 8. Panel B of Table

\footnotetext{
${ }^{23}$ This is because the first difference filter magnifies the very high frequency components of the data, while reducing the relative importance of business cycle frequencies. By comparison, the HP filter resembles a high pass filter that isolates the business cycle frequencies and higher (see, e.g., Christiano and den Haan (1996, section 3) and Singleton (1988)).
} 
8 displays the corresponding statistics computed from the data generated by the aseasonal analog of the baseline seasonal model. The two sets of statistics are only trivially different. In results not reported here, we found that this is also true when seasonal adjustment is done by using deterministic dummies, rather than X11. This failure to find effects linked to seasonality supports the typical practice of specifying aseasonal RBC models and evaluating them with seasonally adjusted data.

\subsection{Robustness Checks}

In this subsection we consider robustness of our results to first differencing and to the alternative seasonal models. The effects of first differencing in the baseline model may be seen by comparing Panels A and B in Table 9. Note that the differences are quite small. So, our key finding that there is no distortion when the artificial data are generated by the baseline model is robust to the use of the first difference filter.

Next, we analyze results for an alternative seasonal model in which the exogenous shock processes for taste, technology and government consumption are switched from their baseline representations to no-dummy representations with a constant term and, respectively, 8, 8, and 9 autoregressive lags. Business cycle statistics computed from seasonally adjusted and HP-filtered data generated by this model are reported in Panel $\mathrm{C}$ of Table 8 . Panel D displays the corresponding statistics computed from the seasonally unadjusted, HP-filtered data generated by the aseasonal analog of this alternative seasonal model. The differences between the two sets of statistics are not always as trivial as before. The analyst computes a contemporaneous hours-productivity correlation in Panel D that is 0.17 higher than the corresponding number in Panel C. Several other dynamic correlations are off by 0.10 or more, especially for investment and output. Furthermore, the analyst substantially understates the volatility of investment. Also, the analyst's points estimates imply that investment lags the cycle, although it is coincident with the cycle in the analyst's "actual" data (see Panel C). Overall, however, the distortions in Panels $\mathrm{C}$ and $\mathrm{D}$ of Table 8 do not seem dramatic. ${ }^{24}$

More dramatic distortions result when the data are generated by the alternative seasonal model and the HP filter is replaced in the analysis by the first difference filter. These

\footnotetext{
${ }^{24}$ This conclusion is sensitive to the length of the autoregressive process for productivity. Recall that the 4-lag representation was ranked as a close second to the 8-lag representation by the Schwarz criterion. When we adjust the alternative seasonal model solely by shortening the length of the productivity autoregression to 4, certain distortions become much larger. For example, the "true" correlation between hours today and productivity yesterday drops from .41 to .15, while the analyst's correlation rises from .57 to .61. The gap between the analyst and the truth thus rises from a moderate .16 in Panel D, Table 8, to a substantial .46, solely due to the shorter autoregressive representation for productivity.
} 
results are reported in Panels $\mathrm{C}$ and $\mathrm{D}$ of Table 9. Note there that the analyst understates the volatility of investment by half. Generally speaking the distortions in the dynamic correlations are now larger than they were in Panels $\mathrm{C}$ and $\mathrm{D}$ of Table 8.

In results not reported here, we found that the technology process is critical to the increased distortions implied by the alternative seasonal model. The results reported in Table 8 change very little if we return the taste and government shock series to their baseline representation but leave the technology series in its alternative representation. If instead we just return the technology shock to its baseline representation, then the distortions become small again, like those in the top two panels of Table 8. So, the evidence of distortion that we find is driven by the alternative seasonal representation of the technology shock. In assessing these distortions, it is important to recall our finding that this representation is rejected by the data.

\section{Concluding Remarks}

We were frankly surprised that a defensible model could be constructed which supports the conventional practice with respect to seasonality in the business cycle literature. Still, there are at least two reasons why our analysis does not settle the issue. First, our seasonal model has shortcomings. We cannot rule out that a superior model that corrects these shortcomings will imply bigger distortions. In exploring modifications, it would be interesting to focus on alternative specifications of the exogenous shocks, such as autoregressions with periodic or stochastically evolving coefficients. ${ }^{25}$ Another plausible route is to explore model modifications which enhance endogenous sources of seasonality. This is consistent with recent findings that seasonal patterns vary with the business cycle (see Canova and Ghysels 1994, Cecchetti, Kashyap, and Wilcox (1997), and Ghysels (1994a).) Second, our analysis has focussed on a fairly simple, basic equilibrium model of business cycles. We think this is valuable for the purpose of setting a benchmark. Still, the literature on equilibrium business cycle models includes wage contracting, heterogeneity of agents, multiple sectors, tax shocks, monetary factors, and modifications designed to reproduce features of asset markets. Whether our findings are relevant for these cases is an open, quantitative, issue that can be addressed using the procedures implemented in this paper.

\footnotetext{
${ }^{25}$ See, for example, Boswijk and Franses (1995,1995a), Franses and Papp (1994, 1999), Ghysels, Hall, and Lee (1996), Ghysels, McCulloch, and Tsay (1998) and Hylleberg and Pagan (1997).
} 


\section{A. The Appropriate Measure of Hours Worked For Seasonal Anal- ysis}

Previous studies of aggregate seasonal fluctuations have focused on a measures of hours worked and productivity derived from the establishment survey of employment. With this measure of employment, labor productivity is low in the third quarter and then very high in the fourth quarter (see row 2 in Table A1). This is puzzling, because it is hard to think of plausible technological factors that can account for this. The observation stimulated various modeling efforts, including attempts to explain the pattern as reflecting increasing returns in technology and/or labor hoarding (see Braun and Evans (1998)).

Table A1 shows that the puzzling productivity results are an artifact of using the establishment employment data. This series treats people on paid vacation as though they were working and experienced workers as though they were no more productive than new employees. Our employment measure, based on a survey of households and adjusted by Gary Hansen (1993) for labor force composition, represents a better indicator of work effort because it measures hours actually worked and adjusts for worker efficiency. According to Hansen's measure, work effort in the third quarter drops substantially, as experienced workers go on vacation and summertime temps are employed (see row 3). The drop in effective hours worked is sufficiently large that our estimate of labor productivity does not display the puzzling seasonal pattern in the third and fourth quarters that results when the establishment-based hours data are used (row 4).

\section{B. Goodness-of-Fit of the Alternative Shock Representation}

In this appendix, we inquire whether the alternative shock models of Section 4.3 can account for the evidence of deterministic seasonality that we find in the shock processes. For this, we use a style of test applied in Christiano and Ljungqvist (1988). In particular, we develop several statistics that quantify the amount of deterministic seasonality in the exogenous shock data, and we ask how hard it is for the alternative seasonal models to account for them. We find that in the case of the taste and (to a lesser extent) technology shocks, the alternative seasonal models can do so only with very low probability. On this basis we reject the purely indeterministic autoregressive representation for these two series. We find that we cannot reject the purely indeterministic representation for the government consumption shock, however.

To carry out our test, we use two types of statistics that characterize the evidence on deterministic seasonality in the exogenous shock processes. We use (i) the t-statistic on the indeterministic seasonal coefficient, $\theta$, in the baseline seasonal models, reported in Table 1. 
This is small in the case of all shocks except the government consumption shock. We also use (ii) statistics that characterize the evidence that the seasonal pattern of ups and downs in the data is stable over time.

The following describes the first of our two statistics of type (ii). For each calendar year we compute the percentage deviations (log difference) of each quarter's observation from the sample mean for that year. We also compute the percentage deviation of each quarter's seasonal dummy from the average of the seasonal dummies. Then, for each year, we compute the correlation between the two series. The average of these annual correlations is our magnitude measure of seasonal stability. For the preference shock, the productivity shock, and the government consumption shock series computed from US data, we obtained magnitude measures of seasonal stability of $0.93,0.98$, and 0.63 , respectively. Thus, for the first two shocks, the pattern of seasonal ups and downs is very stable over time, as would be expected for a process whose seasonal is primarily deterministic. With a seasonal that is primarily indeterministic we might expect to see some drifting in the seasonals, which would produce a low value for the magnitude measure of seasonal stability.

In our second statistic of type (ii), we rank each quarter in a calender year according to the size of the percent deviations discussed in the previous paragraph. The highest quarter in a given year is ranked 1, the second highest 2, and so on. (We also experimented with ranking both middle quarters 2.5 , to allow for seasonal patterns in which middle quarters are not sharply different, but the results changed little and are not reported.) We also rank each quarter's observation according to the magnitude of that quarter's dummy. For each calendar year, we then compute the Spearman rank correlation between the ranking of that year's quarters and the overall ranking based on the dummies. Our rank measure of seasonal stability is the average of these correlations over the whole sample. For the preference shock, the productivity shock, and the government consumption shock series computed from US data, we obtained rank measures of seasonal stability of $0.91,0.92$, and 0.51 , respectively.

To check whether the indeterministic models of seasonality are consistent with the statistics discussed above, we simulated 5,000 artificial data sets, each of the same length as our US data time period ( 25 and a half years, corresponding to $58: 3$ to $83: 4$ ), for each of the estimated purely autoregressive seasonal representations. In each case the period $58: 3$ to 61:2 was set equal to the actual values in our US data series, and the remaining observations were simulated using the fitted purely indeterministic seasonal models and bootstrapping (whereby disturbance terms are obtained by sampling, with replacement, from the fitted residuals). Using the same computations described above, we computed a t-statistic and the two measures of seasonal stability for each simulation. That is, for each autoregressive representation, we obtained 5,000 artificial t-statistics and 5,000 pairs of seasonal stability statistics. 
For the government consumption shock, the artificial $t$-statistics were smaller than the empirical one 17.2 percent of the time. Thus, even at a 10 percent critical level, the autoregressive seasonal representation is not rejected. For the taste shock and productivity shock, however, less than 1 percent of the simulations yield a $t$-statistic smaller than the empirical one, indicating that their estimated autoregressive representations cannot explain away the empirical evidence in favor of deterministic seasonality. In other words, this test rejects the autoregressive seasonal representation for taste and productivity shocks at the 1 percent level.

The results for the magnitude measure of seasonal stability are similar. For government consumption, 12.2 percent of the simulations produced percentage deviation statistics as high as the empirical one. For the taste and productivity shocks, by contrast, less than 1 percent of the simulations did so.

The rank measure of seasonal stability was slightly different. The autoregressive seasonal model for government consumption again was not rejected; 22.4 percent of the simulations produced Spearman measures as high as the empirical one. The opposite was again true for the taste shock, again at the 1 percent critical level. For the technology shock, however, 5.8 percent of the simulations produced Spearman seasonal stability statistics equal to or greater than the empirical measure. At a 5 percent critical level for this statistic, one would (barely) not reject the autoregressive seasonal representation for the productivity shock.

To summarize our results: (i) the tests strongly reject the indeterministic model using taste shocks; (ii) two tests reject the indeterministic model using productivity shocks and one does not; (iii) the tests do not reject the purely indeterministic seasonal model using government consumption.

It is important to emphasize one final point. If we had allowed even longer lags, we could have produced purely indeterministic models consistent with the evidence on deterministic seasonality. This is because long autoregressions can arbitrarily well approximate representations like our baseline models with seasonal dummies. ${ }^{26}$ Such long autoregressions are not of interest in applied work, since they are difficult to estimate with precision in typical postwar data sets.

\footnotetext{
${ }^{26}$ This requires some explanation. Formally, we can think of the spectral density of our baseline time series representation as the sum of the spectrum of $x_{t}^{d}$ and $x_{t}^{n d}$ in (3.8). The latter is well defined. We define the former as the Fourier transform of the covariance function of the dummies that would be computed from a long sample of dummies. This Fourier transform is composed of Delta function spikes. So, the spectrum implied by our baseline model can be thought of as the sum of a smooth part and a Delta function part. A sequence of spectra implied by longer and longer lag autoregressions can approximate this pattern arbitrarily well.
} 


\section{References}

[1] Barro, Robert. 1990. Macroeconomics. John Wiley \& Sons, Inc.

[2] Barsky, Robert B., and Miron, Jeffrey A. 1989. The seasonal cycle and the business cycle. Journal of Political Economy 97, 503-34.

[3] Beaulieu, J. Joseph, and Miron, Jeffrey A. 1991. A cross country comparison of seasonal cycles and business cycles. Manuscript. Boston University (May).

[4] Benhabib, Jess; Rogerson, Richard; and Wright, Wright. 1991. Homework in macroeconomics: Household production and aggregate fluctuations. Journal of Political Economy 99, 1166-187.

[5] Boswijk, H. Peter and Philip Franses. 1995. Periodic cointegration: representation and inference. Review of Economics and Statistics. 77(3), August, pages $436-54$.

[6] Boswijk, H. Peter and Philip Franses. 1995a. Testing for periodic integration. Economics Letters. 48(3-4), June, pages 241-48.

[7] Braun, R. Anton, and Evans, Charles L. 1995. Seasonality and equilibrium business cycle theories. Journal of Economic Dynamics and Control 19, 503531.

[8] Braun, R. Anton, and Evans, Charles L. 1998. Seasonal Solow residuals and Christmas: A case for labor hoarding and increasing returns. Journal of Money, Credit and Banking, vol. 30, no. 3, August, part 1.

[9] Canova, Fabio, and Eric Ghysels. 1994. Changes in seasonal patterns, are they cyclical?, Journal of Economic Dynamics and Control 18: 1143-1171.

[10] Cecchetti, Stephen G., Anil K. Kashyap, and David W. Wilcox. 1997. Interactions between the seasonal and business cycles in production and inventories. American Economic Review. 87(5), December, pages 884-92.

[11] Christiano, Lawrence J. 1988. Why does inventory investment fluctuate so much? Journal of Monetary Economics 21, 247-80.

[12] Christiano, Lawrence J.. 1990. Linear-quadratic approximation and valuefunction iteration: a comparison, Journal of Business and Economic Statistics. 
[13] Christiano, Lawrence J., and Martin Eichenbaum. 1992. Current real business cycle theories and aggregate labor market fluctuations. American Economic Review 78 (June): 430-50.

[14] Christiano, Lawrence J., and Wouter den Haan. 1996. Small-Sample Properties of GMM for Business-Cycle Analysis. Journal of Business and Economic Statistics vol. 14, no. 3, July, pp. 309-327.

[15] Christiano, Lawrence J., and Lars Ljungqvist. 1988. Money does grangercause output in the bivariate output-money relation. Journal of Monetary Economics, September.

[16] Christiano, Lawrence J., and Richard M. Todd. 1996. Time to plan and aggregate fluctuations. Federal Reserve Bank of Minneapolis Quarterly Review, Winter, vol. 20, no. 1.

[17] Cleveland, W.P. and G.C. Tiao. 1976. Decomposition of seasonal time series: a model for the Census X-11 Program. Journal of the American Statistical Association. vol. 71, issue 355, September, pp. 581-587.

[18] Cooley, Thomas F., and Prescott, Edward, 1995. Economic growth and business cycles. In Thomas F. Cooley, ed., Frontiers of business cycle research. Princeton University Press.

[19] Franses, Philip and Richard Paap. 1994. Model selection in periodic autoregressions, Oxford Bulletin of Economics and Statistics. 56(4), November, pages $421-39$.

[20] Franses, Philip and Richard Paap. 1999. On trends and constants in periodic autoregressions. Econometric Reviews. 18(3), August, pages 271-86.

[21] Franses, Philip, Henk Hoek, and Richard Paap. 1997. Bayesian analysis of seasonal unit roots and seasonal mean shifts. Journal of Econometrics. 78(2), June, pages 359-80.

[22] Franses, Philip, Svend Hylleberg and Hahn S. Lee. 1995. Spurious deterministic seasonality. Economics Letters 48, pp. 249-256.

[23] Ghysels, Eric. 1988. A study towards a dynamic theory of seasonality for economic time series. Journal of the American Statistical Association, vol. 83, pp. 168-172. 
[24] Ghysels, Eric. 1994a. On the periodic structure of the business cycle. Journal of Business and Economic Statistics, 12, pp. 289-298.

[25] Ghysels, Eric. 1994b. On the economics and econometrics of seasonality. In C.A. Sims, editor, Advances in Econometrics, vol. 1, Cambridge University Press.

[26] Ghysels, Eric, Clive Granger, and Pierre Siklos. 1996. Is seasonal adjustment a linear or nonlinear data transformation?. Journal of Business and Economic Statistics. 14(3), July, pages 374-86.

[27] Ghysels, Eric, Alastair Hall, and Shik Hahn Lee. 1996. On periodic structures and testing for seasonal unit roots. Journal of the American Statistical Association. 91(436), December, pages 1551-59.

[28] Ghysels, Eric, Robert E. McCulloch, and Ruey S. Tsay. 1998. Bayesian inference for periodic regime-switching models. Journal of Applied Econometrics. 13(2), March-April, pages 129-43.

[29] Grether, D.M., and M. Nerlove. 1970. Some properties of "optimal" seasonal adjustment. Econometrica, v. 38 (no. 5, September), pp. 682-703.

[30] Hansen, Gary D. 1985. Indivisible labor and the business cycle. Journal of Monetary Economics 16 (November): 309-27.

[31] Hansen, Gary D. 1993. The cyclical and secular behavior of the labor input: Comparing efficiency and hours worked, Journal of Applied Econometrics, vol. 8, January-March, pp. 71-80.

[32] Hansen, Gary D., and Wright, Randall. 1992. The labor market in real business cycle theory. Federal Reserve Bank of Minneapolis Quarterly Review 16 (Spring): 2-12.

[33] Hansen, Lars Peter, and Sargent, Thomas J. 1993. Seasonality and approximation errors in rational expectations models. Journal of Econometrics, 55, $21-56$.

[34] Hodrick, Robert, and Edward Prescott. 1997. Post-war business cycles: An empirical investigation. Journal of Money, Credit and Banking, vol. 29, no. 1, February, pp. 1-16. 
[35] Hylleberg, Svend and Adrian R. Pagan. 1997. Seasonal integration and the evolving seasonals model. International Journal of Forecasting. 13(3), September, pages 329-40.

[36] Hylleberg, Svend, Clara Jorgensen, and Nils Karl Sorensen. 1993. Seasonality in macroeconomic time series. Empirical Economics. 18(2), pages 321-35.

[37] King, Robert, and Sergio Rebelo, 1993. Low frequency filtering and real business cycles. Journal of Economic Dynamics and Control, vol. 17, pp. 251-231.

[38] Kydland, Finn E., and Prescott, Edward C. 1982. Time to build and aggregate fluctuations. Econometrica 50, 1345-70.

[39] Lovell, Michael C. 1963. Seasonal adjustment of economic time series, Journal of the American Statistical Association, vol. 58, pp. 993-1010.

[40] Maravall, Agustín. 1995. Unobserved components in economic time series. In Pesaran, M. Hashem, and M.R. Wickens, eds. (1995), Handbook of Applied Econometrics, Volume I: Macroeconomics. Oxford: Blackwell Publishers, Ltd.

[41] McGrattan, Ellen R. 1994. A progress report on business cycle models. Federal Reserve Bank of Minneapolis Quarterly Review, Fall.

[42] Plosser, Charles I. 1979. The analysis of seasonal economic models. Journal of Econometrics, v. 10 (June), pp. 147-163.

[43] Sargent, Thomas, 1978. Comments on 'Seasonal Adjustment and Multiple Time Series Analysis' by Kenneth F. Wallis, in Arnold Zellner (ed.) Seasonal Analysis of Economic Time Series, Proceedings of the Conference on the Seasonal Analysis of Economic Time Series, Washington, D.C., Sept. 9-10, 1976, Economic Research Report, ER-1, US Department of Commerce, Bureau of the Census.

[44] Sargent, Thomas. 1987. Macroeconomic Theory, 2nd edition, Academic Press.

[45] Schwarz, G. 1978. Estimating the dimension of a model. Annals of statistics. 6:461-4. 
[46] Sims, Christopher A. 1976. Response to Sargent's Comment on the Paper by Wallis. unpublished manuscript, November 23.

[47] Singleton, Kenneth J.. 1988. Econometric Issues in the Analysis of Equilibrium Business Cycle Models, Journal of Monetary Economics, vol. 21, pp. 361-386.

[48] Young, A.H. 1968, Linear approximations to the census and BLS seasonal adjustment methods. Journal of the American Statistical Association.

[49] Wallis, Kenneth F. 1974. Seasonal adjustment and relations between variables. Journal of the American Statistical Association, v. 69 (no. 345, March), pp., $18-31$.

[50] Watson, Mark, 1993. Measures of fit for calibrated models. Journal of Political Economy, 101:1011-41. 
Table 1: Exogenous Shock Models ${ }^{1}$

Panel A: Preferences, $\tau$

\begin{tabular}{|c|c|c|c|c|c|c|c|c|c|c|}
\hline & $\sigma_{\varepsilon}$ & $\phi_{1}$ & $\phi_{2}$ & $\theta$ & $e^{d_{1}}$ & $\mathrm{e}^{\mathrm{d}}{ }_{2}$ & $e^{d_{3}}$ & $\mathrm{e}^{\mathrm{d}_{4}}$ & $Q$ & DW \\
\hline Equation 3.9 & .017 & $\begin{array}{r}.49 \\
(4.96)\end{array}$ & $\begin{array}{r}.30 \\
(3.03)\end{array}$ & $\begin{array}{r}.13 \\
(1.16)\end{array}$ & .303 & .302 & .290 & .312 & $\begin{array}{l}.73 \\
(24)\end{array}$ & 2.00 \\
\hline
\end{tabular}

Panel B: Technology, $\lambda$

\begin{tabular}{lcccccccccc} 
& $\sigma_{\varepsilon}$ & $\phi_{1}$ & $\phi_{2}$ & $\theta$ & $\mathrm{d}_{1}$ & $\mathrm{~d}_{2}$ & $\mathrm{~d}_{3}$ & $\mathrm{~d}_{4}$ & $\mathrm{Q}$ & $\mathrm{DW}$ \\
\hline Equation 3.9 & .021 & $\begin{array}{r}-.17 \\
(-1.63)\end{array}$ & $\begin{array}{r}.10 \\
(.98)\end{array}$ & $\begin{array}{c}.08 \\
(.76)\end{array}$ & -.095 & .063 & .025 & .021 & .87 & 1.99
\end{tabular}

Panel C: Government, g

\begin{tabular}{lcrrrrrrrrr} 
& $\sigma_{\varepsilon}$ & \multicolumn{1}{c}{$\phi_{1}$} & \multicolumn{1}{c}{$\phi_{2}$} & $\theta$ & $\mathrm{e}^{\mathrm{d}_{1}}$ & $\mathrm{e}^{\mathrm{d}_{2}}$ & $\mathrm{e}^{\mathrm{d}_{3}}$ & $\mathrm{e}^{\mathrm{d}_{4}}$ & $\mathrm{Q}$ & $\mathrm{DW}$ \\
\hline Equation 3.9 & .024 & $\begin{array}{r}.68 \\
(6.32)\end{array}$ & $\begin{array}{r}.12 \\
(1.18)\end{array}$ & $\begin{array}{c}.21 \\
(1.90)\end{array}$ & 273.9 & 266.3 & 263.2 & 262.8 & .09 & 1.92 \\
& & & & & & & $(24)$ &
\end{tabular}

${ }^{1}$ Equation 3.9 results are for fitting the model, $x_{t}=d_{1} d_{1 t}+d_{2} d_{2 t}+d_{3} d_{3 t}+d_{4} d_{4 t}+\left[\left(1-\phi_{1} L-\phi_{2} L^{2}\right)\left(1-\theta L^{4}\right)\right]^{-1} \varepsilon_{t}$ to $x_{t}$, where $x_{t}=\log \tau_{t}, \lambda_{t}, \log g_{t}$, as indicated, $d_{i t}$ is 1 in quarter $\mathrm{i}$ and zero otherwise, $\mathrm{i}=1,2,3,4$ and $\sigma_{\varepsilon}$ is the standard deviation of $\varepsilon_{\mathrm{t}}$. Calculations done in two steps: dummy coefficients are obtained in step one by OLS over 1958:3 to 1983:4, and in step two the remaining coefficients are obtained by applying RATS procedure BOXJENK to the residuals. The step two regressions are over 1960:1 to 1983:4. With one exception, numbers in parentheses are t-statistics. The exception is the column pertaining to $\mathrm{Q}$, which consists of the number of lags in the Box-Pierce statistic computed on the fitted disturbances. Q is the p-value of the Box-Pierce statistic, with a number below 0.05 indicating rejection at the 5 percent level. DW is the Durbin-Watson statistic. 


\begin{tabular}{||c|c|r|r|r|r|r||}
\hline \multicolumn{7}{||l}{ Table 2: Seasonal Deviations from Trend, U.S. Data } \\
\hline \\
\hline
\end{tabular}

${ }^{1} \mathrm{Y}=$ real GNP, $\mathrm{C}=$ real consumption of nondurables plus services, $\mathrm{I}=$ real fixed investment, $\mathrm{G}=$ real government consumption. From Hansen (1985): $\mathrm{n}=$ effective household hours. Other data from Barsky-Miron (1989). Real variables are Barsky-Miron nominal variables divided by their CPI series. All data were originally in not seasonally adjusted form. They were seasonally adjusted with the default settings in RAT's EZX11, and then logged and HP filtered. The efficiency hours data were provided to us by Gary Hansen. Data period is 1948-85, except 1955-85 for hours and productivity. Where possible, results are reproduced from Barsky and Miron, Table 1. Results for consumption of nondurables and services, C, and for hours worked and productivity were computed by us. Results obtained by first logging and then HP-filtering the data. The transformed data were regressed on seasonal dummies. The table based on the resulting coefficients, after multiplication by 100 .

\begin{tabular}{||r|c|c|c|c||}
\hline \hline \multicolumn{5}{||c|}{ Table 3: Time-to-Build Weights by Season and Stage of Project } \\
\hline & \multicolumn{4}{|c||}{ Season (calendar quarter) } \\
\hline Stage of Project & Q1 & Q2 & Q3 & Q4 \\
\hline Stage Zero & .0237 & .0171 & .0171 & .0171 \\
\hline Stage One & .3924 & .3924 & .3924 & .3924 \\
\hline Stage Two & .1552 & .1552 & .1552 & .1552 \\
\hline Stage Three & .4353 & .4353 & .4353 & .4353 \\
\hline
\end{tabular}

${ }^{1}$ Entries in column headed Qi represent the relative share of resources put in place for investment projects initiated in quarter $i$. The weights add to 1.0 in quarters 2,3 , and 4 . 


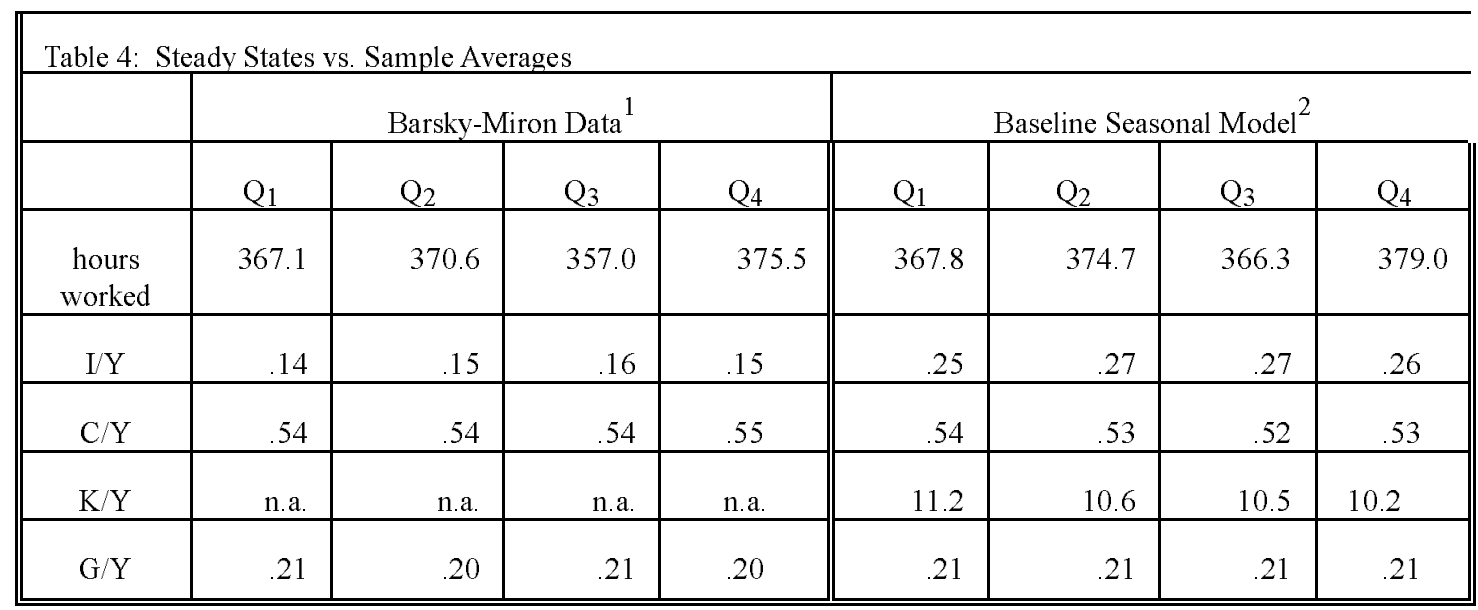

${ }^{1}$ Dummy coefficients in regression of indicated variables on quarterly dummies. For I/Y, C/Y, G/Y the sample period is $1950 \mathrm{Q} 1-1985 \mathrm{Q} 4$.

For hours worked, the efficiency-based measure was used, and the sample period was 1955Q3-1985Q4.

${ }^{2}$ Nonstochastic steady state values of indicated variables.

\begin{tabular}{|c|c|r|r|r|r|r|r||}
\hline \multicolumn{7}{|c|}{ Table 5 Seasonal Cycle, Model and Data } \\
\hline
\end{tabular}

${ }^{1}$ Deviation from HP-trend of logged data (multiplied by 100) along steady state growth path.

${ }^{2}$ Taken from Table 2 for convenience 


\begin{tabular}{|c|c|c|c|c|c|c|c|c|c|}
\hline \multicolumn{10}{|c|}{ Table 6: Selected Statistics, Seasonally Unadjusted Data } \\
\hline \multicolumn{10}{|c|}{ Panel A: U.S. Data for $1948-85$} \\
\hline & & \multirow{3}{*}{$\begin{array}{l}\text { Relative } \\
\text { Volatlity }\end{array}$} & \multicolumn{7}{|c|}{ Dynamic Correlations } \\
\hline \multicolumn{2}{|c|}{ Variables } & & \multicolumn{7}{|c|}{$\mathrm{X} 1(\mathrm{t})$ with $\mathrm{X} 2(\mathrm{t}-\mathrm{j})$ for $\mathrm{j}=$} \\
\hline $\mathrm{X} 1$ & $\mathrm{X} 2$ & & 3 & 2 & 1 & 0 & -1 & -2 & -3 \\
\hline $\mathrm{Y}$ & $\mathrm{Y}$ & .038 & -.20 & .29 & .00 & 1.00 & .00 & .29 & -.20 \\
\hline $\mathrm{Y}$ & $\mathrm{C}$ & .92 & -.21 & .17 & -.26 & .88 & -.14 & .15 & -.35 \\
\hline $\mathrm{Y}$ & $\mathrm{I}$ & 2.17 & -.27 & .30 & .38 & .78 & -.05 & .32 & .18 \\
\hline $\mathrm{Y}$ & $\mathrm{n}$ & .67 & -.11 & .58 & -.30 & .63 & .16 & .77 & -.33 \\
\hline $\mathrm{Y}$ & G & 1.48 & -.28 & -.11 & -.12 & .34 & -.11 & .10 & .09 \\
\hline $\mathrm{n}$ & $\mathrm{Y} / \mathrm{n}$ & 1.16 & -.25 & .59 & .26 & -.06 & -.33 & .42 & .05 \\
\hline \multicolumn{10}{|c|}{ Panel B: Baseline Seasonal Model } \\
\hline $\mathrm{Y}$ & $\mathrm{Y}$ & .035 & -.27 & .25 & -.15 & 1.0 & -.15 & .25 & -.27 \\
\hline $\mathrm{Y}$ & $\mathrm{C}$ & .94 & -.12 & .33 & -.46 & .80 & -.09 & .27 & -.56 \\
\hline $\mathrm{Y}$ & $\mathrm{I}$ & 1.98 & -.39 & .09 & .11 & .81 & -.22 & .16 & .07 \\
\hline $\mathrm{Y}$ & $\mathrm{n}$ & .53 & -.24 & .50 & -.41 & .72 & -.07 & .60 & -.42 \\
\hline $\mathrm{Y}$ & $\mathrm{G}$ & 1.21 & -.06 & .16 & -.08 & .75 & .04 & .12 & -.09 \\
\hline $\mathrm{n}$ & $\mathrm{Y} / \mathrm{n}$ & 1.35 & -.27 & .43 & .14 & .27 & -.34 & .29 & -.02 \\
\hline
\end{tabular}

1/Entry corresponding to $\mathrm{Y}$ is the standard deviation of (logged, detrended) output. Entries in the following five rows are the standard deviation of the $\mathrm{X} 2$ variable relative to the standard deviation of the $\mathrm{X} 1$ variable. 


\begin{tabular}{|c|c|c|c|c|c|c|c|c|c|}
\hline \multicolumn{10}{|c|}{ Panel A: Baseline Seasonal Model } \\
\hline & & \multirow{3}{*}{$\begin{array}{l}\text { Relative } \\
\text { Volatility }\end{array}$} & \multirow{2}{*}{\multicolumn{7}{|c|}{$\begin{array}{l}\text { Dynamic Correlations } \\
\mathrm{X} 1(\mathrm{t}) \text { with } \mathrm{X} 2(\mathrm{t}-\mathrm{j}) \text { for } \mathrm{j}=\end{array}$}} \\
\hline \multicolumn{2}{|c|}{ Variables } & & & & & & & & \\
\hline $\mathrm{X} 1$ & $\mathrm{X} 2$ & & 3 & 2 & 1 & 0 & -1 & -2 & -3 \\
\hline $\mathrm{Y}$ & $\mathrm{Y}$ & .019 & .39 & 61 & .79 & 1.00 & .79 & .61 & .39 \\
\hline $\mathrm{Y}$ & $\mathrm{C}$ & .94 & .27 & .44 & .52 & .66 & .35 & .26 & .14 \\
\hline $\mathrm{Y}$ & $\mathrm{I}$ & 2.15 & .26 & .40 & .57 & .71 & .76 & .62 & .44 \\
\hline $\mathrm{Y}$ & $\mathrm{n}$ & .62 & .18 & .31 & .45 & .72 & .69 & .58 & .41 \\
\hline $\mathrm{Y}$ & $\mathrm{G}$ & 1.85 & .29 & .42 & .57 & .71 & .51 & .37 & .21 \\
\hline $\mathrm{n}$ & $\mathrm{Y} / \mathrm{n}$ & 1.14 & .43 & .53 & .56 & .13 & .23 & .14 & .09 \\
\hline
\end{tabular}

Panel B: Data From Aseasonal Analog of Model in Panel A

\begin{tabular}{|c|c|r|r|r|r|r|r|r|r||}
\hline $\mathrm{Y}$ & $\mathrm{Y}$ & .019 & .39 & .61 & .78 & 1.00 & .78 & .61 & .39 \\
\hline $\mathrm{Y}$ & $\mathrm{C}$ & .94 & .27 & .42 & .49 & .65 & .34 & .26 & .14 \\
\hline $\mathrm{Y}$ & $\mathrm{I}$ & 2.16 & .26 & .42 & .59 & .72 & .75 & .62 & .44 \\
\hline $\mathrm{Y}$ & $\mathrm{n}$ & .63 & .16 & .32 & .45 & .72 & .66 & .55 & .39 \\
\hline $\mathrm{Y}$ & $\mathrm{G}$ & 1.87 & .30 & .44 & .55 & .71 & .50 & .37 & .21 \\
\hline $\mathrm{n}$ & $\mathrm{Y} / \mathrm{n}$ & 1.11 & .44 & .53 & .56 & .14 & .25 & .19 & .11 \\
\hline \hline
\end{tabular}

Panel C: Alternative Seasonal Model

\begin{tabular}{||c|c|r|r|r|r|r|r|r|r||}
\hline $\mathrm{Y}$ & $\mathrm{Y}$ & .021 & .43 & .62 & .80 & 1.00 & .80 & .62 & .43 \\
\hline $\mathrm{Y}$ & $\mathrm{C}$ & .91 & .41 & .46 & .51 & .56 & .34 & .23 & .15 \\
\hline $\mathrm{Y}$ & $\mathrm{I}$ & 2.66 & .14 & .33 & .50 & .70 & .65 & .54 & .40 \\
\hline $\mathrm{Y}$ & $\mathrm{n}$ & .69 & .06 & .26 & .45 & .72 & .61 & .52 & .42 \\
\hline $\mathrm{Y}$ & $\mathrm{G}$ & 1.81 & .37 & .48 & .57 & .69 & .52 & .40 & .26 \\
\hline $\mathrm{n}$ & $\mathrm{Y} / \mathrm{n}$ & 1.00 & .59 & .54 & .41 & .03 & .19 & .15 & .08 \\
\hline
\end{tabular}

Panel D: Data from Aseasonal Analog of Model in Panel C

\begin{tabular}{||c|c|r|r|r|r|r|r|r|r||}
\hline $\mathrm{Y}$ & $\mathrm{Y}$ & .020 & .47 & .65 & .81 & 1.00 & .81 & .65 & .47 \\
\hline $\mathrm{Y}$ & $\mathrm{C}$ & .86 & .36 & .45 & .54 & .69 & .39 & .27 & .17 \\
\hline $\mathrm{Y}$ & $\mathrm{I}$ & 2.09 & .31 & .49 & .63 & .77 & .80 & .70 & .55 \\
\hline $\mathrm{Y}$ & $\mathrm{n}$ & .60 & .20 & .37 & .48 & .74 & .68 & .59 & .47 \\
\hline $\mathrm{Y}$ & $\mathrm{G}$ & 1.79 & .37 & .49 & .59 & .73 & .54 & .42 & .26 \\
\hline $\mathrm{n}$ & $\mathrm{Y} / \mathrm{n}$ & 1.14 & .52 & .55 & .57 & .20 & .28 & .23 & .13 \\
\hline
\end{tabular}

Panels $\mathrm{A}$ and $\mathrm{C}$ are based on artificial data simulated from the indicated models and then seasonally adjusted using the Census X-11 procedure implemented in RATS' EZX11. Panels B and D are based on data simulated from aseasonal analogs to the models underlying Panels A and C. All data were logged and hp-filtered prior to computing the statistics. See the notes to Table 7 for further discussion of the format of this table 
Table 9: Effect of Seasonal Adjustment on Selected Business Cycle Statistics Using First-Difference Detrending Instead of HP Filtering

Panel A: Baseline Seasonal Model

\begin{tabular}{|c|c|c|c|c|c|c|c|c|c|}
\hline & & \multirow{3}{*}{$\begin{array}{l}\text { Relative } \\
\text { Volatility }\end{array}$} & \multicolumn{7}{|c|}{ Dynamic Correlations } \\
\hline \multicolumn{2}{|c|}{ Variables } & & \multicolumn{7}{|c|}{$\mathrm{X} 1(\mathrm{t})$ with $\mathrm{X} 2(\mathrm{t}-\mathrm{j})$ for $\mathrm{j}=$} \\
\hline $\mathrm{X} 1$ & $\mathrm{X} 2$ & & 3 & 2 & 1 & 0 & -1 & -2 & -3 \\
\hline $\mathrm{Y}$ & $\mathrm{Y}$ & .013 & .09 & .22 & .07 & 1.00 & .07 & .23 & .09 \\
\hline Y & $\mathrm{C}$ & 1.35 & .03 & .21 & -.03 & .71 & -.24 & .10 & .02 \\
\hline $\mathrm{Y}$ & $\mathrm{I}$ & 2.05 & .09 & .02 & .16 & .32 & .50 & .19 & .16 \\
\hline $\mathrm{Y}$ & $\mathrm{n}$ & .93 & .04 & .02 & -.12 & .45 & .15 & .12 & .09 \\
\hline $\mathrm{Y}$ & $\mathrm{G}$ & 2.19 & .06 & .14 & .02 & .68 & -.05 & .11 & .00 \\
\hline $\mathrm{n}$ & $\mathrm{Y} / \mathrm{n}$ & 1.09 & .03 & .08 & .46 & -.47 & .19 & -.01 & -.02 \\
\hline
\end{tabular}

Panel B: Data From Aseasonal Analog of Model in Panel A

\begin{tabular}{|c|c|c|c|c|c|c|c|c|c|}
\hline $\mathrm{Y}$ & $\mathrm{Y}$ & .013 & .06 & .23 & .03 & 1.00 & .03 & .23 & .06 \\
\hline $\mathrm{Y}$ & $\mathrm{C}$ & 1.37 & .03 & .18 & -.07 & .72 & -.25 & .12 & -.03 \\
\hline $\mathrm{Y}$ & $\mathrm{I}$ & 1.97 & .03 & .08 & .19 & .32 & .48 & .19 & .20 \\
\hline $\mathrm{Y}$ & $\mathrm{n}$ & .95 & -.05 & .07 & -.15 & .48 & .11 & .12 & .06 \\
\hline $\mathrm{Y}$ & $\mathrm{G}$ & 2.26 & .06 & .14 & -.02 & .67 & -.07 & .12 & -.02 \\
\hline $\mathrm{n}$ & $\mathrm{Y} / \mathrm{n}$ & 1.05 & .13 & .08 & .44 & -.47 & .18 & .04 & .02 \\
\hline
\end{tabular}

Panel C: Alternative Seasonal Model

\begin{tabular}{|c|c|c|c|c|c|c|c|c|c|}
\hline $\mathrm{Y}$ & $\mathrm{Y}$ & .015 & .18 & .18 & .09 & 1.00 & .09 & .19 & .18 \\
\hline $\mathrm{Y}$ & $\mathrm{C}$ & 1.36 & .28 & .07 & .07 & .45 & -.08 & .04 & .12 \\
\hline $\mathrm{Y}$ & $\mathrm{I}$ & 3.47 & -.12 & .08 & .03 & .46 & .17 & .11 & .07 \\
\hline $\mathrm{Y}$ & $\mathrm{n}$ & 1.05 & -.14 & .04 & -.05 & .55 & .02 & .06 & .09 \\
\hline $\mathrm{Y}$ & $\mathrm{G}$ & 1.98 & .21 & .13 & .04 & .63 & .01 & .12 & .11 \\
\hline $\mathrm{n}$ & $\mathrm{Y} / \mathrm{n}$ & .92 & .27 & .09 & .28 & -.51 & .21 & .07 & .04 \\
\hline
\end{tabular}

Panel D: Data from Aseasonal Analog of Model in Panel C

\begin{tabular}{|c|c|c|c|c|c|c|c|c|c|}
\hline $\mathrm{Y}$ & $\mathrm{Y}$ & .014 & .20 & .23 & .09 & 1.00 & .09 & .23 & .21 \\
\hline $\mathrm{Y}$ & $\mathrm{C}$ & 1.31 & .16 & .10 & -.01 & .73 & -.17 & .06 & .05 \\
\hline $\mathrm{Y}$ & $\mathrm{I}$ & 1.87 & .04 & .23 & .17 & .39 & .44 & .27 & .32 \\
\hline $\mathrm{Y}$ & $\mathrm{n}$ & .92 & -.05 & .13 & -.15 & .51 & .09 & .10 & .14 \\
\hline $\mathrm{Y}$ & $\mathrm{G}$ & 2.15 & .17 & .12 & .03 & .67 & -.03 & .14 & .05 \\
\hline $\mathrm{n}$ & $\mathrm{Y} / \mathrm{n}$ & 1.04 & .22 & .05 & .42 & -.43 & .18 & .07 & .02 \\
\hline
\end{tabular}

Panels $\mathrm{A}$ and $\mathrm{C}$ are based on artificial data simulated from the indicated models and then seasonally adjusted using the Census $\mathrm{X}-11$ procedure implemented in RATS' EZX11. Panels B and D are based on data simulated from aseasonal analogs to the models underlying Panels A and C. All data were logged and first differenced prior to computing the statistics. See the notes to Table 7 for further discussion of the format of this table. 


\begin{tabular}{|c|c|c|c|c|c|c|c|}
\hline & \multicolumn{4}{|c|}{ Average Percentage Deviation by Quarter } & \multirow[b]{2}{*}{$\begin{array}{l}\text { Dummies' } \\
\text { Std. Dev. } \\
\end{array}$} & \multicolumn{2}{|c|}{ Dummies' Correlations } \\
\hline & Q1 & Q2 & Q3 & Q4 & & $\begin{array}{l}\text { With Y } \\
\text { Dummies }\end{array}$ & $\begin{array}{l}\text { With Y/n } \\
\text { Dummies }\end{array}$ \\
\hline $\mathrm{n}$, est & -2.14 & .21 & 1.01 & 1.16 & 1.53 & .82 & .58 \\
\hline $\mathrm{Y} / \mathrm{n}$, est & -1.62 & .33 & -1.37 & 2.71 & 2.00 & .93 & \\
\hline $\mathrm{n}, \mathrm{eff}$ & -.07 & .86 & -2.90 & 2.14 & 2.14 & .52 & -.17 \\
\hline Y/n, eff & -3.76 & -.48 & 2.27 & 1.76 & 2.74 & .72 & \\
\hline
\end{tabular}

${ }^{1}$ Hours data are distinguished by source: "est" means establishment survey and "eff" means Hansen's (1985) effective household hours. See notes to Table 2 for further details 
Figure 1a: Preference Shock, $\tau$

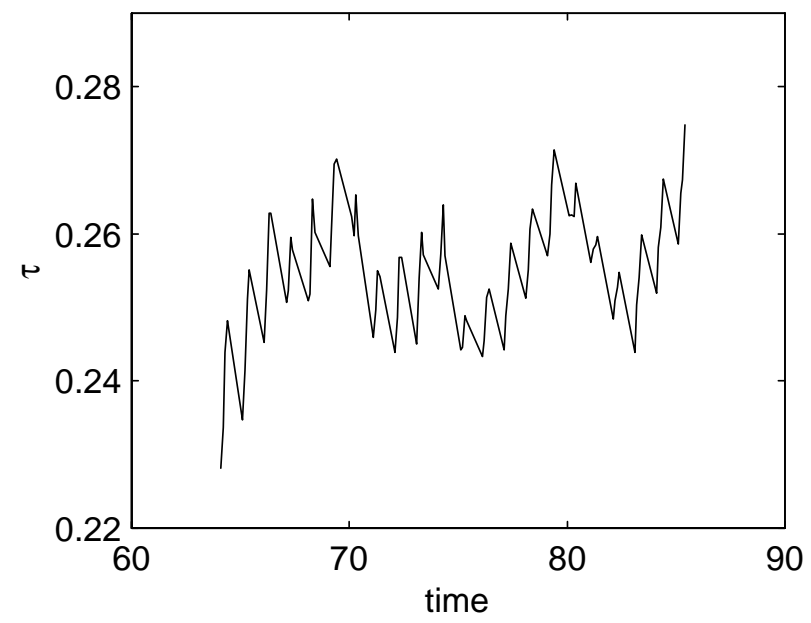

Figure 1c: Detrended gov't consumption (G/z)

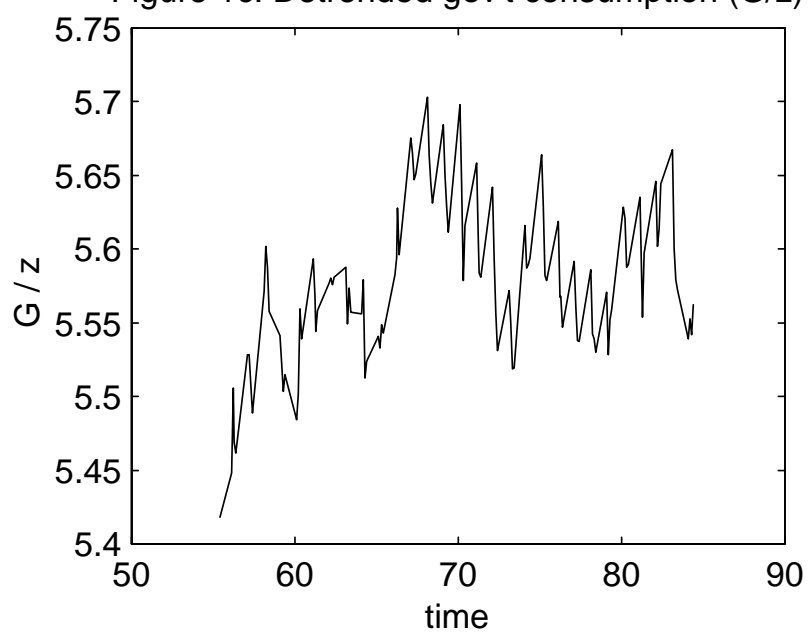

Figure 1b: Technology Growth, $\lambda$

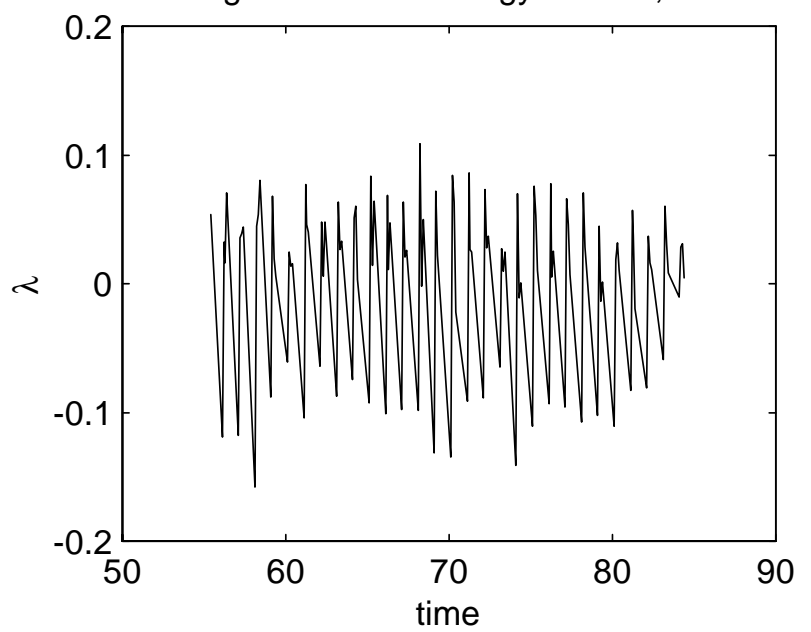


Figure 2a: Tastes, $\tau$

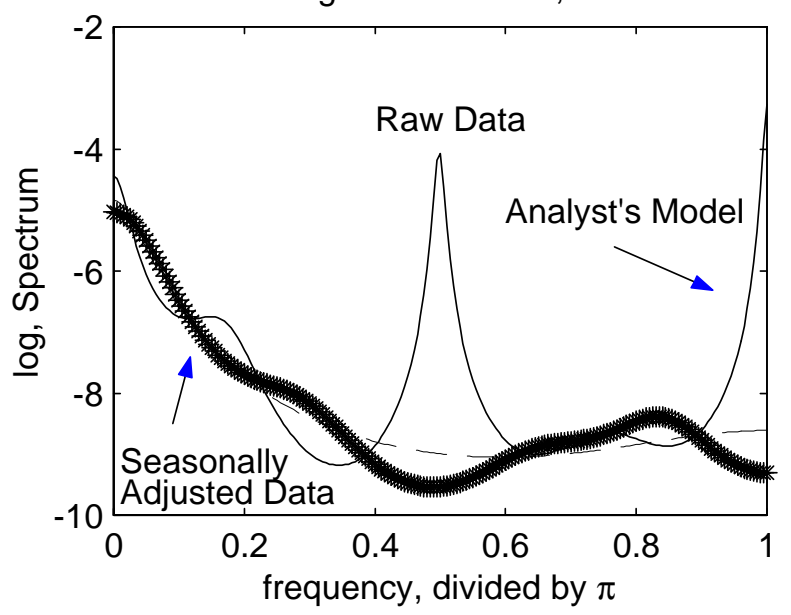

Figure 2c: G/z

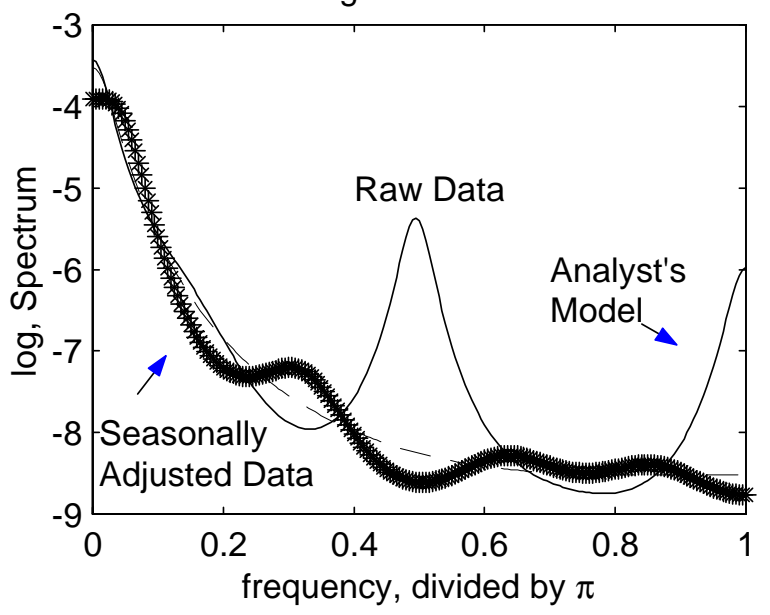

Figure 2b: Technology growth, $\lambda$

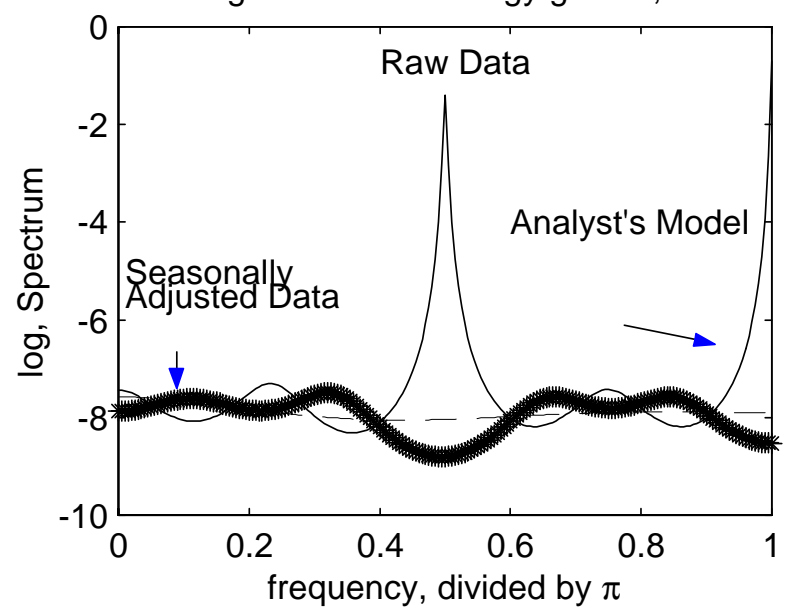

